IZA DP No. 5794

Workforce Reorganization and the Worker

Ben Kriechel

Gerard A. Pfann

June 2011 


\title{
Workforce Reorganization and the Worker
}

\author{
Ben Kriechel \\ ROA, Maastricht University \\ and IZA \\ Gerard A. Pfann \\ Maastricht University, \\ CEPR and IZA
}

\section{Discussion Paper No. 5794 \\ June 2011}

\author{
IZA \\ P.O. Box 7240 \\ 53072 Bonn \\ Germany \\ Phone: +49-228-3894-0 \\ Fax: +49-228-3894-180 \\ E-mail: iza@iza.org
}

Any opinions expressed here are those of the author(s) and not those of IZA. Research published in this series may include views on policy, but the institute itself takes no institutional policy positions.

The Institute for the Study of Labor (IZA) in Bonn is a local and virtual international research center and a place of communication between science, politics and business. IZA is an independent nonprofit organization supported by Deutsche Post Foundation. The center is associated with the University of Bonn and offers a stimulating research environment through its international network, workshops and conferences, data service, project support, research visits and doctoral program. IZA engages in (i) original and internationally competitive research in all fields of labor economics, (ii) development of policy concepts, and (iii) dissemination of research results and concepts to the interested public.

IZA Discussion Papers often represent preliminary work and are circulated to encourage discussion. Citation of such a paper should account for its provisional character. A revised version may be available directly from the author. 
IZA Discussion Paper No. 5794

June 2011

\section{ABSTRACT}

\section{Workforce Reorganization and the Worker}

In this paper we study the joint decision process of changing the structure of jobs and laying off individual workers in a firm that downsizes its workforce. A hierarchical decision model is proposed and estimated using personnel data from a firm in demise comparing the characteristics of the individual workers and the structure of the firm's labour force before and after its reorganization. Our results show that workers in jobs in the top levels of each skill group's hierarchy are better protected against downsizing due to larger productivity shocks and larger firing costs.

JEL Classification: J63, J65, L23, L60, L93, M51

Keywords: hierarchies, restructuring, control span, job displacement

Corresponding author:

Ben Kriechel

Maastricht University

ROA

P.O. Box 616

6200 MD Maastricht

The Netherlands

E-mail: ben@kriechel.eu

\footnotetext{
* We would like to thank Fokker's bankruptcy trustees, especially Ben Knüppe, for making the personnel data available, and Louis Deterink for sharing with us his profound knowledge and insights on corporate through-starts. We benefited from comments received during presentations at the universities of Bonn, Essex, Oxford, Porto, Tilburg, Toulouse, and London as well as at conference workshops in Chicago, Mannheim, and Vienna. We are grateful to Melvyn Coles, Dan Hamermesh, Jim Malcomson, Jan van Ours, Dennis Snower, Uwe Sunde, and Bas ter Weel for their helpful comments.
} 


\section{Introduction}

This paper studies the role of job structure when a firm decides to downsize its workforce. Despite the long tradition of research on the economies of organizational hierarchies, surprisingly little is known about the role of hierarchies in firms' decisions to restructure their workplace. Hierarchies are often understood as efficient outcomes of personnel assignment policies, ${ }^{1}$ and their role in the determination of the distribution of earnings within the firm is fundamenta.$^{2}$ Adaptations in the organizational structure of the firm may be prompted by technological innovations, especially when adjustments to shocks require changes in specialization. Workplace reforms can then be characterized by adjustments of the hierarchical structure of jobs. ${ }^{3}$

Our contribution is twofold: First, we analyze the reorganization process. The decision process of changing the structure of jobs and of laying off individual workers is taken jointly. For this, we use personnel data from a large industrial firm. The restructuring of the firm's workplace is done as part of a bankruptcy spin-off and involves substantial downsizing. Within the firm the organization of work is divided between skill groups with separate hierarchical job structures and personnel dynamics. There are no immediate adjustments in individual wages. During the reorganization, there is no substitution of skills and the structure of jobs remained the same such that there is no decrease in the height of the hierarchical pyramid. The number of workers at successive levels was, however, affected in such a way that control spans changed.

A second contribution of this paper is that we relax the strict assumption of rescaling in the hierarchical pyramid structures. While recent theoretical models of hierarchical organizations have assumed that the downsizing involves a rescaling of the pyramidal structure leaving the relative

\footnotetext{
${ }^{1}$ Alchian and Demsetz (1972); Calvo and Wellisz (1979); MacLeod and Malcomson (1988).

${ }^{2}$ Marshak and Radner (1972); Medoff and Abraham (1980); Rosen (1982); Baker, Gibbs and Holmstrom (1994).

${ }^{3}$ Radner (1992), Rajan and Wulf (2006).
} 
span of control among different levels unchanged, ${ }^{4}$ we relax this assumption in our model estimation. We find evidence against the assumption of monotonicity of the downsizing decision, i.e. the downsizing affects the levels of the firm differently. Fixed costs, such as firing cost, imply a composite response to shocks. This is based on the prediction from modern dynamic factor input models under uncertainty that a firm's management will be in favour of large and infrequent changes in the workplace.$^{5}$ This lumpiness of downward employment adjustments is often argued to be caused by large transaction costs that such operations involve. A firm will not adjust the productive workforce after each single shock in, for example, technology, demand or labour market policy. Irreversible costs of adjustment are the driving force behind waiting until a sufficiently large number of different shocks render restructuring profitable or inevitable. If at some point the corporate management decides to restructure the workforce, what will then be observed in the data is the simultaneous and composite response to the collection of past shocks.

We investigate the composite effects of two different shocks: policy shocks that relate to employment protection legislation and shocks to productivity. Our results show that jobs in the top levels of each skill group's hierarchy benefit more from productivity enhancing shocks and are better protected against downsizing risk through firing costs. In reorganizations, both effects increase the distance of average earnings of the two skill groups. While the productivity effect may be the most well-known, the effect of employment protection on the increasing wage discrepancy is less well-known but significant as well.

The paper is organized as follows. The data are introduced in Section 2. Section 3 presents the hierarchical decision model. Section 4 presents the estimation results and the outcomes of model specifications tests. In Section 5, the results of a simulation analysis of shocks in firing costs are shown. Section 6 concludes.

\footnotetext{
${ }^{4}$ See e.g. Rosen (1982), Ferrall (1997), Garicano (2000).

5 See Hamermesh and Pfann (1996) for an early survey of this literature. Pfann (2006) presents a simple structural labour demand model with heterogeneity of firing costs and productivity across workers but without job structure.
} 


\section{A firm in demise}

The empirical labour market literature repeatedly makes the distinction between high skilled and low skilled workers or blue collar and white collar jobs to illustrate differences in adjustment costs. In most large firms, however, the inputs of different productive skills are often characterized by distinct job structures with separate internal labour market dynamics. The simple distinction between high and low skills conceals the role of hierarchies in the decision process to change the organization of the workplace.

Fokker, a technologically advanced aircraft building company with headquarters in Amsterdam, was declared bankrupt on Friday March 15, 1996. The data we use for this study incorporates the records of all tenured workers employed on the day of the bankruptcy in all three restructured plants. The reorganization took place over the weekend of March 16 and 17, 1996. On Monday March 18, the trustees rehired 20 percent of the former workers in those three plants. The other workers were permanently laid off. In the reorganization process, the total number of dismissals was dictated by the aim to maximize the value of the reorganized firm. The personnel trustees were responsible for the subsequent selection process of workers ${ }^{6}$.

\section{[INSERT TABLE 1]}

Table 1 presents the input of manual and non-manual workers before and after the reorganization. Precise determination of skill groups is often quite difficult. In our data the firm's internal labour market is characterized by two different ports of entry: one for manual workers and

\footnotetext{
${ }^{6}$ See Deterink et al. (1997) for the precursors' report and for an in depth description of the firm's reorganization.
} 
one for non-manual workers. We refer to the two types of workers as skill groups, as they had their own hierarchical structure and their own career patterns ${ }^{7}$ Table 1 shows the input ratio of two manual to one non-manual worker. The ratio of manual to non-manual worker remained unaltered after the downsizing.

\section{[INSERT TABLE 2]}

Table 2 shows means and SD of hourly wages for all workers as well as separate statistics for women and men, for low and high education, below or above medium tenure, and below and above average age. On average, we find an increase of 1.9 percentage points in the overall hourly compensation between skill groups. The increase, however, is much larger for low educated young workers with below-median tenure, and especially for women.

\section{[INSERT TABLE 3]}

Table 3 shows that before as well as after the organizational change manual workers are educated less than non-manual workers and that the average educational level is higher for more authoritative levels in both skill groups ${ }^{8}$. Manual workers operate in three hierarchical levels (team workers, team leaders, and heads of production teams); non-manual workers operate in five levels. However, due to small sample sizes we merged the upper two levels yielding in total four levels (assistant engineers, engineers, senior engineers, managers).

\section{[INSERT TABLE 4]}

\footnotetext{
${ }^{7}$ See Dohmen et al. (2004) for a comprehensive description of the data.

${ }^{8}$ A theoretical explanation for the finding that more complicated tasks -- of non-manual workers -- coincide with an increase in the height of the hierarchical pyramid is discussed in Garicano (2000).
} 
Table 4 shows the changes in the hierarchical job structure for each skill group. We find indeed that even though the number of workers at different hierarchical sublevels changed, the pyramidal form of the workforce remained unaffected and no sublevels disappeared (no flattening). However, control spans did not increase or decrease monotonically. Restructuring firms face large and mostly sunk transaction costs. Such costs will induce the firm's management to postpone substantial restructurings ${ }^{9}$. Once the reorganization is imminent, however, one observes the compounded response to a collection of various shocks. This response may not only affect the relative demand for individual workers, but may also lead to differences in the adjustment of control spans as well. The bankruptcy provided the one time opportunity to adjust the workforce without the adjustment cost. However, future adjustment costs are taken into account.

\section{Specification of the Hierarchical Decision Model}

Fig. 1 presents the tree structure of the hierarchical decision model. Three interrelated levels of decisions can be distinguished: ( $i$ ) the allocation of workers to jobs in manual and nonmanual skill levels; (ii) the hierarchical organization within these two levels; and (iii) the lay-off decision of heterogeneous workers in a given hierarchical level of a given skill group. This sequence of decisions can be described by a hierarchical decision model (Tversky, 1972) expressed in the latent random profitability form so that the resulting choices are consistent with an optimal decision process under uncertainty (McFadden, 1984; Small, 1987). However, the hierarchical decision model presented in this paper is an extension of these models with the Lazear and Rosen (1981) feature of corporate hierarchies being built into it.

[INSERT Fig. 1]

\footnotetext{
${ }^{9}$ See Pindyck (1991) for a lucid explanation of the role of sunk fixed costs on the decision to wait to invest.
} 
Suppose that the latent profitability $\Pi_{i h s}$ of worker $i$ in level $h$ of skill group $s$ is random and can be written as

$\Pi_{i h s}=Z_{h s} \alpha+X_{i} \beta \kappa_{h s}+\varepsilon_{i h s} \equiv V_{i h s}+\varepsilon_{i h s} \quad$ with $s=1, \ldots, S ; h\left|s=1, . ., H_{s} ; i\right| h s=1, \ldots, N_{h s}$

where $S$ is the number of skill groups, $H_{s}$ denotes the height of the hierarchical pyramid of skill group $s$, with $h=1$ being the top level; and $N_{h s}$ the number of workers in level $h$ of skill group $s$. $Z_{h s}$ is a matrix of level specific characteristics, $X_{i}$ is a vector of worker specific attributes, $\alpha$ and $\beta$ are constant parameter vectors. Let $G\left(e^{V}\right)=\sum_{h=1}^{H_{s}}\left[\sum_{i=1}^{N_{h s}} \exp \left(V_{i h s} / \kappa_{h s}\right)\right]^{\kappa_{h s}}$ be a generating function for response probabilities. When $0<\kappa_{h s} \leq 1$, with $\kappa_{h s}$ being a measure of independence of alternative choices in each level, and $\varepsilon_{i}$ follows the distribution $F(\varepsilon)=\exp \left(-G\left(e^{-\varepsilon}\right)\right)$, the worker selection model is consistent with the assumption of profit maximization under uncertainty ${ }^{10}$ The probability of choosing worker $i$ from level $h$ of skill group $s$ to stay has a nested probability form and can be written as the conditional probability of selecting that worker from a specific level $h s$ :

$\operatorname{Pr}\left(\Pi_{i h s}>0 \mid h, s\right)=\exp \left(X_{i} \beta \mid h, s\right) /\left(1+\exp \left(X_{i} \beta \mid h, s\right)\right)$

times the probability worker $i$ is in level $h$. We follow Lazear and Rosen (1981) and assume that if worker $i$ is assigned to job-level $h$ and worker $j$ is assigned to the lower job-level $h+1$, it holds that $\mathrm{E}\left[\Pi_{i h s} \mid s\right]>\mathrm{E}\left[\Pi_{j h+1 s} \mid s\right]$. The positive relation between hierarchical position and higher individual productivity is, as in Lazear and Rosen (1981) the result of an allocation through merit-based promotions.

Then the probability given in equation 2 is ordered and yields the nested ordered probability $^{11}$

\footnotetext{
${ }^{10}$ See Boskin (1974) for an early application of conditional logit to optimal occupational choice under uncertainty. ${ }^{11}$ See Marshak (1959) for the formal derivation of a single level ordered model in MNL form that is subject to the restrictive Independence from Irrelevant Alternatives (IIA) feature. See Small (1987) for formal derivations of the two-level nested multinomial logit (NMNL) model. Our model reduces to the simple MNL model with the IIA feature under the restriction of $\kappa_{h s}=1$.
} 


$$
\operatorname{Pr}\left(\Pi_{i h s} \mid s\right)=\prod_{h=1}^{H_{s}-1}\left[\exp \left(Z_{h s} \alpha+J_{h s} \kappa_{h s}\right) / \sum_{m=h}^{H_{s}} \exp \left(Z_{m s} \alpha+J_{m s} \kappa_{m s}\right)\right]
$$

where $J_{h s} \equiv \log \left(\sum_{i \in h}\left(1+\exp \left(X_{i} \beta\right)\right)\right)$ defines the inclusive value of workers in level $h$ of skill type $s$. $J_{h s} \kappa_{h s}$ can be interpreted to reflect the minimum productivity level for a given worker to be kept within the level.

Production technology is changed through variation in factor input ratios. Here it is sufficient to assume that the input ratios of different skill groups are fixed. This assumption is motivated by the statistics presented in the previous section, which suggests that the workforce reorganization was not inspired by a substantial change in production technology, but has been a production costs reducing operation. The result is a two-level nested ordered hierarchical decision model with $\theta \equiv\left(\alpha, \beta, \kappa_{h s}\right)$ being the model's parameters. The model determines the size of the hierarchical level, and by ordering the workers productivity based on $X$ given $Z$, it also determines the selection of workers into hierarchies.

We suggest a two-step estimation procedure to obtain estimates for $\theta$ as in Maddala (1983, p67-88) and Wooldridge (2002). First, estimate $\beta$ by applying conditional logit with the hierarchical levels as the group indicator. Second, compute $\hat{J}_{h s}$ and estimate $\alpha$ and $\kappa_{h s}$ by maximum likelihood. We slightly modify the second step of the common estimation procedure to allow for the ordered nature of the hierarchical levels and estimate (3) in ordered form with $\gamma_{h s} \equiv J_{h s} \kappa_{h s}$ being the profit thresholds separating the hierarchical levels, and $\gamma_{1 s}>\gamma_{2 s}>\ldots>\gamma_{H_{s}}$. The model requires a normalization restriction, which is $\gamma_{H_{s}}=0$, so that $\gamma_{1 s}>\ldots>\gamma_{H_{s}-1}>0$. It reduces to the standard multinomial logit model with the independence of irrelevant alternatives (IIA) feature under testable parameter restrictions. A hierarchical model specification test yields $\kappa_{h s} \leq 1$ and a 
test of the IIA feature yields $\kappa_{h s}=1$ for all $h \in\left\{1, \ldots, H_{s}-1\right\}$. These tests are performed in the empirical analysis.

\section{An Econometric Investigation of the Model}

The hierarchical decision model incorporates two sets of explanatory variables. One set of variables, included in the matrix $Z$, contains level specific characteristics. The other set, included in the matrix $X$, exists of worker specific attributes.

\section{Level specific characteristics: technological innovation}

The literature on corporate hierarchies discusses only a handful of possible causes for the observed changes in the delegation of authorities. Since the sophistication of information technologies at the workplace renders the provision of information and the decision making of middle managers obsolete, technology shocks are associated with a decrease in the relative size of the middle management in large organizations (Pinsonneault and Kraemer, 1997). This is consistent with the results presented in Table 4 where we observed decreases in the span of control of team leaders (M2) and of engineers (NM2). Increases in the use of information technology can increase the span of control of managers ( $c f$. Garicano, 2000). In Table 4 this assertion is supported for heads of production teams (M3), and for senior engineers (NM3), but not of managers (NM4). Rajan and Wulf (2006) argue that changes in information technologies may eventually lead to a complete elimination of some of the hierarchical levels. Although not observed in the data used for this paper, the model presented here does allow for the probability of 'flattening' of hierarchical structures. 
Whether profits are increasing or decreasing the wage change is positively related to the profit change (Pfann, 2006). As a consequence, $\Delta W_{h s(t)}$ is a good proxy for the impact of changing productivity on profits. $\Delta W_{h s(t)}$ is computed as the level-specific hourly wage growth over a period of three years preceding the bankruptcy, averaged over all workers that were employed at the day of the bankruptcy. During this period, the firm did not hire new workers. The growth rate of hourly wages for manual workers is 0.8 percent and 1.2 percent for non-manual workers. The wage growth difference between the two skill groups thus yields 0.4 percentage points.

\section{Level specific characteristics: transaction costs}

The literature on intermittent adjustment of the workforce at the firm level focuses primarily on the importance of fixed transactions costs. Transaction costs of workforce reductions are associated with severance pay. Severance pay or, more generally, firing costs are influenced by job security policies ${ }^{12}$ Termination of employment legislation determines severance payments in association with the legal term of notice $(T o N)$. In the Netherlands, employment protection rules are legally defined in Articles 1639i and 1639j of the Netherlands Civil Code and Article 40.3 of the Bankruptcy Act. The $T o N$ is equal to the time that passes between two consecutive earnings instalments not extending a period of six weeks. The minimum $T o N$ for tenured workers is the number of weeks equal to the number of years employees have worked full time for the same employer since adulthood, but not extending a period of 13 weeks. The $T o N$ is extended with one week for every full year of employment of workers of age 45 years or older, but not extending a period of 13 weeks. The legal maximum $T o N$ is therefore equal to 26 weeks.

\footnotetext{
${ }^{12}$ See Table 8.2 in Hamermesh (1993) for a list of international studies on the effects of job-security policies. Oyer and Schaefer (2002) show that changes in employment protection policies can change the distribution of wages and employment across members of protected groups of workers. Pfann (2006) shows that lay-off decisions depend strongly on the distribution of heterogeneous firing costs.
} 
Fig. 2 shows the ToN and firing costs for all hierarchical levels of both skill groups on March 15, 1996. For manual workers the average is 12.0 weeks ( $\mathrm{SD}=4.4)$; for non-manual workers the average is 11.9 weeks $(\mathrm{SD}=5.1)$ weeks. Note that $T o N$ increases by with the hierarchical level. For manual workers the average firing costs are 11940 Dutch guilders ( $\mathrm{SD}=5400)$; for non-manual workers the average is 20770 Dutch guilders $(S D=12610)$. Moreover, firing costs also increase with each hierarchical levels and rise steeper than ToN.

[INSERT Fig. 2]

\section{Worker specific attributes}

The downsizing process followed a set of rules formulated around three different types of worker attributes: performance indicators related to performance on the job, behavioural characteristics related to conduct in the work context, and social criteria related to fairness quota that were agreed upon prior to restructuring in negotiations with the worker councils ${ }^{13}$ External observers were assigned to each selection team to guarantee compliance with these rules, to warrant objectivity in the decisional process, and to prevent maintaining 'old-boys-networks'. Primary goal was, however, to create a workforce that allowed for a maximization of expected future profits. This to create revenue when the 'leaner' bankruptcy spin-off of the company were to be sold by the bankruptcy trustees.

We observe all administrative data that is underlying the decision process. However, we are in our estimation ignorant of any information that was only informally known to the selection team. We use the following information: Performance indicators listed as criteria for the selection

\footnotetext{
${ }^{13}$ The Fokker bankruptcy involved the largest displacement of workers in the history of the Netherlands. Because of this unique situation, the trustees consulted teams of department heads and representatives of the workers council and the appropriate unions to formulate selection rules.
} 
teams included annual job performance ${ }^{14}$ scores, ranging between 1 (bad) and 6 (excellent); tenure being measured in years; and education being measured in nine education levels, as well as a dummy variable for the education being primarily vocational. The educational composition of the firm's workforce reflects the traditional industrial character of the firm's production technology: $69 \%$ of all workers had vocational schooling. Language skills were also listed as performance indicators, but the personnel data did not contain information on this aspect so that we cannot include it in the estimation.

Behavioural characteristics listed as criteria for the selection teams were communication skills, mental flexibility, creativity, interest in other people, need for structure, emotional stability, self-confidence, frustration tolerance, being a team-worker, leadership, and learning capacity. Most of these items are not available in the personnel data files. Taken together, they reflect a superior's perception of the worker's ability to implement tasks, to take responsibility, and citizenship. This perception is partially revealed by the assignment of workers to on-the-job training courses. The firm offered two types of training courses to enhance firm-specific knowledge of the production process and to improve general skills; $90 \%$ of all manual workers followed one or more internal courses and $44 \%$ followed one or more external courses; for non-manual workers these numbers are $84 \%$ and $64 \%$, respectively. Finally, the variable commuting distance (in kilometres) is related to the - unpaid - time a worker invests daily to go to work and may also be interpreted as a behavioural characteristic.

Social criteria or fairness quota included (partial or temporary) disability, cultural minority groups, single mothers, families with husband and wife both working at the same firm and the age distribution in general. Information on marriage to a coworker, the number of children, or race is not available in the personnel data, but it does contain information on age, gender $(1=f e m a l e$;

\footnotetext{
${ }^{14}$ Names of variables are put in italics as they appear in the Tables.
} 
$0=$ male), marital status (not married=0, including divorce; married $=1$ ), as well as information on temporary partial disability (in \%).

\section{[INSERT TABLE 5]}

The upper part of Table 5 reports the parameter estimates $\hat{\beta}$ that belong to the worker specific attributes and measures the conditional probability to select a worker to stay with the company. Workers with higher performance evaluation scores were facing lower lay-off risks, but higher educated workers were separated more. This last effect was also observed in Table 3 where the average education of non-manual workers decreased relatively a bit more than of manual workers. As for the behavioural characteristics, two factors are found to be significant. The number of internal training courses increased the lay-off probability. This indicates that internal courses were meant to train those workers whose initial talents were developed less than that of their peers, but those lags have not been quite made up. Commuting distance coincides with lower lay-off risks indeed. This result supports the idea that the willingness to travel further for the same job is considered to be a positive behavioural aspect. Even though social criteria played an important role in the whole reorganization process the firm still preferred to retain younger workers, while being married turned out to reduce the lay-off risk significantly.

The lower part of Table 5 presents the nested ordered logit estimates of the level specific characteristics included in $Z$. The positive signs of the parameters that belong to the effect of productivity change (\% hourly wage growth) and to the transaction costs (firing costs) suggest that both variables have higher values at higher levels. A positive sign thus means that an increase in the corresponding variable reduces the relative sizes at lower levels. With the number of levels being constant (no flattening), this indicates the reorganization narrowed the bottom of the 
pyramid relative to the top, which indicates an overall decline in authority across the entire hierarchy.

Non-monotonic changes in job structures

In Section 4 of the paper we discussed various interdisciplinary views on how variations in transactions cost and in the effects technological innovations across levels will induce changes in the distribution of authority (the control span), and that those changes may not be monotonic across the entire hierarchical set-up of the firm. To illustrate this, we have examined the effects of shocks in firing costs. Note that a similar exercise for productivity enhancing technology shocks (shocks in hourly wage growth) would yield comparable results.

\section{[INSERT Fig. 3]}

Fig. 3 shows the predicted probability curves holding all the explanatory variables in the model constant except firing costs. The relative sizes of hierarchical levels indeed change nonmonotonically in response to shocks in firing costs. The graphs for the bottom level (M1 and NM1) are sloping downward in both cases. This means that the larger firing costs are the bigger will be the decline of the lower levels relative to the upper ones. The graph for the second level from below (M2 and NM2, the middle management of manual and non-manual workers, respectively) is non-monotonic for both skill groups. When firing costs increase, first the control span with respect to the bottom level increases. But after some turning point the graphs of M1 and M2 and of NM1 and NM2 start moving downwards together, implying that the change in control span will take place higher up in the hierarchy. Fig. 3 shows the effect of firing costs - caused, for example, by a policy shock that changes the term of notice or shocks in heterogeneous wage costs 
- on the firm's organizational design. If firing costs increase and the firm restructures its workplace, it will do so in a way that shifts profits from the lower to the higher levels of the hierarchical job structure for the simple reason that firing workers in higher levels is more costly. That effect is non-monotonic across hierarchical levels.

The restructuring did not result in a substitution of better protected workers for less protected workers. In fact, what happened turned out to be quite the contrary. The firm chose to restructure its hierarchical workforce in favour of workers employed in jobs that were characterized by higher hourly wages with higher productivity and higher firing costs. This has been observed for both manual and non-manual skill groups.

One could argue that the two variables included in $Z$, hourly wage growth and firing costs, are also important predictors of individual lay-off risks. One way to test this is to include both variables in the first step of the regression when the conditional individual probability of being retained is estimated using worker specific attributes. The parameter estimate for firing costs in the conditional logit regression is 0.042 with a SE of 0.086 , and is not significantly different from zero. The parameter estimate for the hourly wage change is 0.302 with a SE of 0.093 , which is significant. To choose which model describes the underlying decision process better, we computed the compound log-likelihood values in both cases. The model that includes the hourly wage change in $X$ (and not in $Z$ ) estimates one parameter less and has a log-likelihood value of -6386.03 while the model that includes the hourly wage change in $Z$ (and not in $X$ ) has a log-likelihood value of 6086.51. From this we conclude that the latter model, being the one reported in Table 5, is the model that explains the data more accurately.

[INSERT TABLE 6] 
The estimates for the profit thresholds $\hat{\gamma}_{h s}$ together with the inclusive values $\hat{J}_{h s}$ are given

in Table 6. Estimates for $\hat{\kappa}_{h s}$ can be obtained from $\hat{\kappa}_{h s}=\hat{\gamma}_{h s} / \hat{J}_{h s}$. The estimates $\hat{\kappa}_{h s}$ can be regarded as a model's specification test. For $0<\kappa_{h s}<1$, cross-elasticities are biggest for workers in the same $h$ and $s$ level. Values of $\kappa_{h s}>1$ may indicate that the assumed ordering is not specified correctly and may point an incorrectly specified hierarchical decision structure. We find that $\hat{\kappa}_{12}$ is the only independence parameter that outside the unit interval. Aggregation may explain this result. As we have noted before level one for non-manual workers actually exists of two joint levels - managers and heads of departments - that were merged to obtain a large enough subsample.

\section{Restructuring and the Earnings Distribution inside the Firm}

We can use the data that underlie the graphs in Fig. 3 to simulate the effects on the distribution of earnings between manual and non-manual workers inside the firm caused by respective changes in firing costs. The simulation exercise is conducted as follows. First, we computed the average hourly wage for all hierarchical levels. The predicted probabilities presented in Fig. 3 allow us to compute the composition of the hourly wage distribution for each skill group relative to the change in firing costs. The observed changes in the earnings distribution then originate from modifying compositions of levels within skill groups. Suppose that the changes are similar for both skill groups. We can then portray how the earnings between skill groups change because of changes in firing costs. The simulation outcomes are presented in Fig. 4.

[INSERT Fig. 4] 
Fig. 4 shows that an increase in firing costs increases hourly wages for manual as well as for non-manual workers, but the latter increase is more substantial. The earnings difference increases with the size of the change in firing costs. The mechanism that produces this result is as follows. The highest levels in both skill groups have the lowest chance to be reduced because their firing costs are higher compared to those of other levels in the same skill group. The earnings difference between the top level of manual workers and the top level of non-manual workers is larger than that between the bottom levels. Increases in firing costs will shift the relative demand toward the upper hierarchical levels, thus increasing the average earnings within each skill group as well as enhancing the earnings difference between skill groups. Firing costs offer better protection to the workers in jobs that are assigned to higher levels of the organization.

\section{Conclusions}

If one wants to understand changes in the labour market, it is necessary to understand what is going on inside firms. This paper studies in detail the restructuring of a large multi-plant firm's workforce. While many workers were displaced - the restructuring was part of a bankruptcy and involved the largest mass lay-off in the history of the Netherlands -, the input ratio of manual to non-manual workers before and after restructuring remained unchanged. Looking more closely at the job structures of manual and non-manual workers we find changes in authority that have not been predicted by economic models of workplace organization, but that indeed were found earlier in management studies. The paper shows that non-monotonic changes in the control spans, where the authority of top and lower management is increased while the authority of the middle management declines, can be explained as the compound result of technological innovations and large transaction costs. 
A discrete decision model that incorporates the features of hierarchical organizational structure is estimated using a rich personnel dataset of a downsizing Dutch aircraft manufacturer. We find that jobs in the upper hierarchical levels of each skill group benefit most from productivity enhancing shocks. Moreover, firing costs offer better protection to the workers in jobs that are assigned to higher levels of the organization. Increases in firing costs as well as increases in productivity will shift the relative demand toward jobs in the upper hierarchical regions, which will increase the average earnings for each skill group. Since the difference in productivity between the top levels of manual workers and non-manual workers is larger than between the lower levels, these shifts in demand caused by increases in firing costs and productivity will also enhance the earnings difference between skill groups.

Although data from only one firm have been used in this study, some general remarks are warranted. First, the fact that restructuring costs are large and largely sunk implies that observed organizational changes may constitute composite responses to different shocks. Future developments of theoretical assignment models that accommodate such responses may yield nonmonotonic adjustments of authority across hierarchical levels. Second, when the introduction of innovations in communication technology or production technology at the workplace coincide with changes in the structure of jobs, biases in favour of specific skills can result from shocks in productivity (e.g. Bresnahan et al., 2002), but can result also from heterogeneity in the - sunk firing costs that such reorganizations entail.

\section{References}

Alchian, A.A. and Demsetz, H. (1972) Production, information costs, and economic organization, American Economic Review, 62, 777-95.

Baker, G., Gibbs, M. and Holmstrom, B. (1994) Internal economics of the firm: evidence from personnel data, Quarterly Journal of Economics, 109, 921-55. 
Boskin, M.J. (1974) A conditional logit model of occupational choice, Journal of Political Economy 82, 389-98.

Bresnahan, T.F., Brynjolfsson, E. and Hitt, L.M. (2002) Information technology, workplace organization, and the demand for skilled labor: firm-level evidence, Quarterly Journal of Economics, 117, 339-76.

Card, D. and DiNardo, J.E. (2002) Skill-biased technological change and rising wage inequality, Journal of Labor Economics, 20, 733-83.

Calvo, G.A. and Wellisz, S. (1979) Hierarchy, ability, and income distribution, Journal of Political Economy, 87, 991-1010.

Deterink, L., Schimmelpenninck, R. Leufting, A. and Knüppe, B. (1997) Bankruptcy trustees' investigation of the causes of the bankruptcy of N.V. Koninklijke Nederlandse Vliegtuigfabriek Fokker, Fokker Aircraft B.V. and Fokker Administration B.V., Kluwer Publishers, Deventer.

Dohmen, T.J., Kriechel, B. and Pfann, G.A. (2004) Monkey bars and ladders: the importance of lateral and vertical movements in internal labor market careers. Journal of Population Economics, 17, 193-228.

Garicano, L. (2000) Hierarchies and the organization of knowledge in production, Journal of Political Economy, 108, 874-904.

Ferrall, C. (1997) Empirical analysis of occupational hierarchies. Journal of Human Resources, 32, 1-34.

Hamermesh, D.S. (1989) Labor demand and the structure of adjustment costs, American Economic Review, 79, 674-89.

Hamermesh, D.S. (1993) Labor demand, Princeton University Press, Princeton.

Hamermesh, D.S. and Pfann, G.A. (1996) Adjustment costs in factor demand, Journal of Economic Literature, 34, 1264-92.

Katz, L.F. and Murphy, K.M. (1992): Changes in relative wages, 1963-1987: supply and demand factors, Quarterly Journal of Economics, 107, 35-78.

Lazear, E.P., and Rosen, S. (1981) Level-order tournaments as optimum labor contracts, Journal of Political Economy, 89, 841-64.

MacLeod W. B. and Malcomson, J.M. (1988) Reputation and hierarchy in dynamic models of employment, Journal of Political Economy, 96, 832-54.

Marshak, J. (1959) Binary-choice constraints and random utility indicators, Cowles Foundation Paper 155, in: Mathematical Methods in the Social Sciences, Stanford University Press, Stanford, 312-29.

Marshak, J., and Radner, R. (1972) Economic theory of teams, Cowles Foundation for Research in Economics Monograph 22, Yale University Press, New Haven.

McFadden, D.L. (1984) Econometric analysis of qualitative response models, in: Griliches, Z. and Intriligator, M.D. (Eds), Handbook of econometrics, Volume II, North-Holland, Amsterdam, 1396-1457.

Medoff, J.L. and Abraham, K.G. (1980) Experience, performance, and earnings, Quarterly Journal of Economics, 95, 703-36. 
Oyer, P., and Schaefer, S. (2002) Litigation costs and returns to experience, American Economic Review, 92, 683-705.

Pfann, G.A. (1989) The structure of adjustment costs for labour, Economics Letters, 29, 365-71.

Pfann, G.A. (2006) Downsizing and heterogeneous firing costs, Review of Economics and Statistics, 88, 158-70.

Pindyck, R.S. (1991) Irreversibility, uncertainty, and investment, Journal of Economic Literature, 29, 111048.

Pinsonneault, A. and Kraemer, K.L. (1997) Middle management downsizing: an empirical investigation of the impact of information technology, Management Science, 43, 659-79.

Radner, R. (1992) Hierarchy: the economics of management, Journal of Economic Literature, 30, 1382415.

Rajan, G.R. and Wulf, J. (2006) The flattening firm: evidence from panel data on the changing nature of corporate hierarchies, Review of Economics and Statistics, 88, 759-73.

Small, K.A. (1987) A discrete choice model for ordered alternatives, Econometrica, 55, 409-24.

Rosen, S. (1982) Authority, control, and the distribution of earnings, Bell Journal of Economics, 13, 31123.

Tversky, A. (1972) Choice by elimination, Journal of Mathematical Psychology, 9, 341-67.

Wooldridge, J.M. (2002) Econometric analysis of cross section and panel data, MIT Press, Cambridge. 
Table 1. Inputs of skills before and after restructuring of the workplace

\begin{tabular}{|c|c|c|c|c|c|c|}
\hline & \multicolumn{2}{|c|}{ Manual workers } & \multicolumn{2}{|c|}{ Non-manual workers } & \multicolumn{2}{|c|}{ Total } \\
\hline & $N_{l}$ & $\begin{array}{l}\text { Shares per } \\
\text { row / column }\end{array}$ & $N_{2}$ & $\begin{array}{c}\text { Shares per } \\
\text { row / column }\end{array}$ & $N$ & $\begin{array}{c}\text { Shares per } \\
\text { row / column }\end{array}$ \\
\hline Total & 3531 & $.655 / 1.0$ & 1858 & $.345 / 1.0$ & 5389 & $1.0 / 1.0$ \\
\hline Selected & 705 & $.656 / .20$ & 370 & $.344 / .20$ & 1075 & $1.0 / .20$ \\
\hline Displaced & 2826 & $.655 / .80$ & 1488 & $.345 / .80$ & 4314 & $1.0 / .80$ \\
\hline
\end{tabular}

Notes: This Table shows the numbers of workers employed in two different skill levels before the realization of the restructuring plan, after the selection had taken place, as well as the number of workers affected by the reorganization of the workforce of Fokker. 
Table 2. Average hourly wages of manual and non-manual workers

\begin{tabular}{|c|c|c|c|c|c|c|c|c|}
\hline & & & $\begin{array}{r}\text { Fri } \\
03 / 15\end{array}$ & & & $\begin{array}{r}\text { Mor } \\
03 / 18\end{array}$ & & $\begin{array}{c}\text { Change } \\
\text { (in percent points) }\end{array}$ \\
\hline & Skill $^{1}$ & NM & $\mathbf{M}$ & NM/M & NM & M & $\mathbf{N M} / \mathbf{M}$ & \\
\hline All workers & Mean & 45.52 & 26.62 & 1.71 & 46.31 & 26.59 & 1.74 & 1.9 \\
\hline & St.Dev & 11.96 & 4.13 & 2.90 & 12.37 & 4.11 & 3.01 & 3.8 \\
\hline & & & & & Men & & & \\
\hline Women & Mean & 40.49 & 24.72 & 1.64 & 42.57 & 23.91 & 1.78 & 8.7 \\
\hline & St.Dev & 9.72 & 3.64 & 2.67 & 9.93 & 4.26 & 2.33 & -12.7 \\
\hline Men & Mean & 45.80 & 26.85 & 1.71 & 46.56 & 26.91 & 1.73 & 1.4 \\
\hline & St.Dev & 12.02 & 4.12 & 2.91 & 12.49 & 3.98 & 3.14 & 7.7 \\
\hline & & & & & $\mathbf{o n}^{2}$ & & & \\
\hline Educ:low & Mean & 42.45 & 26.56 & 1.60 & 43.54 & 26.59 & 1.64 & 2.4 \\
\hline & St.Dev & 9.23 & 4.10 & 2.25 & 10.54 & 4.08 & 2.58 & 14.7 \\
\hline Educ:high & Mean & 46.84 & 26.85 & 1.74 & 47.70 & 26.56 & 1.80 & 2.9 \\
\hline & St.Dev & 12.74 & 4.21 & 3.03 & 13.00 & 4.25 & 3.06 & 1.1 \\
\hline & & & & & & & & \\
\hline Tenure:low & Mean & 42.38 & 24.95 & 1.70 & 42.92 & 24.81 & 1.73 & 1.8 \\
\hline & St.Dev & 10.66 & 3.69 & 2.89 & 11.04 & 3.33 & 3.32 & 14.8 \\
\hline Tenure:high & Mean & 49.53 & 28.35 & 1.75 & 50.29 & 28.61 & 1.76 & 0.6 \\
\hline & St.Dev & 12.34 & 3.83 & 3.22 & 12.69 & 3.98 & 3.19 & -1.0 \\
\hline & & & & & & & & \\
\hline Age:low & Mean & 39.40 & 25.42 & 1.55 & 39.97 & 25.45 & 1.57 & 1.3 \\
\hline & St.Dev & 8.11 & 3.51 & 2.31 & 7.92 & 3.23 & 2.45 & 6.0 \\
\hline Age:high & Mean & 50.46 & 28.16 & 1.79 & 51.52 & 28.29 & 1.82 & 1.6 \\
\hline & St.Dev & 12.29 & 4.34 & 2.83 & 12.94 & 4.66 & 2.77 & -2.0 \\
\hline
\end{tabular}

Notes:

${ }^{1} \mathrm{NM}=$ non-manual workers; $\mathrm{M}=$ manual workers

${ }^{2}$ Education: high is 8: higher vocational schooling, or 9: university;

3 Tenure: low is below median tenure of 15 years;

${ }^{4}$ Age: low is below average age of 39 years. 
Table 3. Education of manual and non-manual workers in different hierarchical levels

\section{Manual Workers}

\section{Hierarchical Level}

M1: Team Worker

M2: Team Leader

M3: Head Production Team

All M

Friday
03/15/1996
3.53
$(1.39)$
4.71
$(1.58)$

5.49

(1.68)

4.11

(1.67)

\section{Non-Manual Workers}

\section{Friday \\ 03/15/1996 \\ 6.84 \\ (1.74)}

NM1 : Assistant Engineer

NM2 : Engineer

NM3 : Senior Engineer

NM4 : Manager
7.57

(1.62)

7.86

(1.53)

8.17

(1.37)

7.40

(1.70)

\author{
Monday \\ 03/18/1996 \\ 3.48 \\ (1.45) \\ 4.71 \\ (1.69) \\ 5.18 \\ (1.70) \\ 3.99 \\ (1.68)
}

Monday
$03 / 18 / 1996$
6.65
$(1.70)$
7.51
$(1.61)$
7.82
$(1.28)$
7.94
$(1.74)$
7.31
$(1.69)$

Notes: The general schooling degrees, like basic education, lower, intermediate and higher general schooling degrees are prerequisites for pursuing a given vocational or general education in the Dutch educational system. Basic education is a prerequisite for any other degree. After having completed basic education, it is possible to either follow a lower vocational schooling course or to attend any of the school forms leading to a general schooling degree. Lower general education (mavo) makes one eligible to follow intermediate vocational training or complete an apprenticeship. An intermediate general schooling degree qualifies for higher vocational schooling, a higher general schooling degree (havo) qualifies for higher vocational schooling (hbo), while the highest level general schooling degree is a prerequisite for pursuing a college or university degree. In addition, it is possible to pursue the next higher schooling level after having obtained a given schooling degree; similarly it is possible to enter the next higher level of vocational schooling after having completed vocational schooling at the level just below, e.g., after having completed intermediate vocational schooling one is eligible to enter higher vocational schooling. (see: Dohmen et al. 2004). Education description: 1=Basic education; $2=$ Lower vocational degree; $3=$ Lower general schooling degree; 4=Apprenticeship; $5=$ Intermediate general schooling degree; $6=$ Intermediate vocational degree; $7=$ Higher general schooling degree; $8=$ Higher vocational degree; $9=$ University degree. 
Table 4. Changes in organizational design

Manual Workers

\begin{tabular}{|c|c|c|c|c|c|c|}
\hline \multirow[b]{2}{*}{ Hierarchical Level } & \multicolumn{2}{|c|}{$\begin{array}{c}\text { Friday } \\
03 / 15 / 1996\end{array}$} & \multicolumn{2}{|c|}{$\begin{array}{c}\text { Monday } \\
03 / 18 / 1996\end{array}$} & \multicolumn{2}{|c|}{$\begin{array}{c}\text { Change } \\
\text { (in \%) }\end{array}$} \\
\hline & Size & Authority & Size & Authority & $\Delta \mathbf{S}$ & $\Delta \mathbf{A}$ \\
\hline M1: Team Worker & 2281 & - & 496 & - & 22 & - \\
\hline M2: Team Leader & 765 & 2.98 & 187 & 2.65 & 24 & -11 \\
\hline M3: Head Production Team & 548 & 1.40 & 84 & 2.23 & 15 & 59 \\
\hline
\end{tabular}

\section{Non-Manual Workers}

\begin{tabular}{|c|c|c|c|c|c|c|}
\hline & \multicolumn{2}{|c|}{$\begin{array}{c}\text { Friday } \\
03 / 15 / 1996\end{array}$} & \multicolumn{2}{|c|}{$\begin{array}{c}\text { Monday } \\
03 / 18 / 1996\end{array}$} & \multicolumn{2}{|c|}{$\begin{array}{c}\text { Change } \\
\text { (in \%) }\end{array}$} \\
\hline & Size & Authority & Size & Authority & $\Delta \mathbf{S}$ & $\Delta \mathbf{A}$ \\
\hline NM1 : Assistant Engineer & 803 & - & 148 & - & 18 & - \\
\hline NM2 : Engineer & 505 & 1.59 & 107 & 1.38 & 21 & -13 \\
\hline NM3 : Senior Engineer & 360 & 1.40 & 65 & 1.65 & 18 & 18 \\
\hline NM4 : Manager & 207 & 1.74 & 52 & 1.25 & 25 & -28 \\
\hline
\end{tabular}

Notes: The table shows the number of workers at the different hierarchical levels before as well as after the restructuring had taken place. Authority is computed as the number of workers in a particular level divided by the number of workers in the level above for a given skill type (control span). $\Delta \mathrm{S}$ is the size selected workers as a percentage of the people working at that hierarchical level before the reorganization. $\Delta \mathrm{A}$ is the percentage change in authority at each hierarchical level. 
Table 5. Estimation results

PART I: Conditional logit estimates of firing probabilities based on worker specific attributes

variable

Performance indicators

evaluation score

tenure

education

vocational dummy

Behavioral characteristics

internal courses

external courses

distance (in km)

Social criteria

age

female

married

disability (in \%)

$N$

PART I $-\log (L)$

$$
\text { mean [SD] }
$$

$6.579 \quad[1.297]$

14.568 [7.831]

5.329 [2.312]

0.686 [0.464]

6.604 [6.736]

1.057 [1.506]

$39.090 \quad[8.286]$

$0.088 \quad$ [0.284]

0.613 [0.481]

2.525 [14.664] estimate (SE)

$-0.165(0.030)$

$0.001 \quad(0.008)$

$0.061 \quad(0.026)$

$0.156 \quad(0.091)$

$0.016(0.007)$

$0.051 \quad(0.028)$

$\mathbf{- 0 . 0 6 3}(0.018)$

$0.025(0.008)$

$0.081 \quad(0.149)$

$\mathbf{- 0 . 2 4 1}(0.084)$

$0.003 \quad(0.004)$

$-2166.71$

PART II: Nested ordered logit estimates based on level specific characteristics

\begin{tabular}{|c|c|c|c|c|}
\hline & \multicolumn{2}{|c|}{ Manual workers } & \multicolumn{2}{|c|}{ Non-manual workers } \\
\hline & mean [SD] & estimate (SE) & mean [SD] & estimate (SE) \\
\hline \multicolumn{5}{|c|}{ Technological innovation - productivity } \\
\hline hourly wage growth (in \%) & $0.778[0.459]$ & $1.276(0.046)$ & $1.177[0.646]$ & $0.617(0.028)$ \\
\hline \multicolumn{5}{|c|}{ Transactions costs } \\
\hline firing costs (in 10,000 Dfl) & $1.194[0.540]$ & $2.463 \quad(0.094)$ & $2.077[1.261]$ & $1.514(0.058)$ \\
\hline$N$ & \multicolumn{2}{|c|}{3594} & \multicolumn{2}{|c|}{1875} \\
\hline PART II - Log $L$ & \multicolumn{2}{|c|}{-1701.41} & \multicolumn{2}{|c|}{-2218.39} \\
\hline
\end{tabular}

Notes: SD in squared brackets; SE in parentheses; Coefficients with $p$-value $<0.05$ are in bold. 
Table 6. Thresholds, inclusive values, and independence parameters

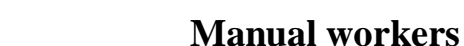

threshold inclusive independence parameter value

parameter
Manual workers

Level $1 \quad \gamma_{31}=0 \quad \hat{J}_{31}=8.165$ $\begin{array}{rrr}\text { Level } 2 & \hat{\gamma}_{21}=6.088 & \hat{J}_{21}=7.096 \\ (0.191) & {[1.274]}\end{array}$

Level $3 \quad \hat{\gamma}_{11}=7.745$

Level 4

\section{Non-manual workers}

$\begin{array}{ccc}\text { threshold } & \begin{array}{c}\text { inclusive } \\ \text { value }\end{array} & \begin{array}{c}\text { independence } \\ \text { parameter }\end{array}\end{array}$

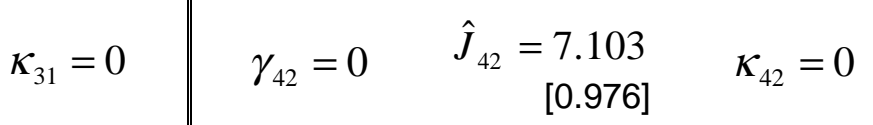

$\hat{\kappa}_{21}=0.699$

$\hat{\gamma}_{32}=5.416$

$\hat{J}_{32}=6.676 \quad \hat{\kappa}_{32}=0.654$

$(0.216)$

[0.856] (0.048)

$\hat{\gamma}_{22}=7.283 \quad \hat{J}_{22}=6.352 \quad \hat{\kappa}_{22}=0.937$

(0.248)

[0.798]

(0.058)

$\hat{\gamma}_{12}=9.668 \quad \hat{J}_{12}=5.700 \quad \hat{\kappa}_{12}=1.386$

(0.308) [0.790]

Notes: $\hat{\gamma}_{h s}$ is the maximum likelihood estimate of the threshold of level $h$ for skill $s ; \hat{J}_{h s}$ is the estimate of the inclusive value; and $\hat{\kappa}_{h s}=\hat{\gamma}_{h s} / \hat{J}_{h s}$. SE are given between brackets. 


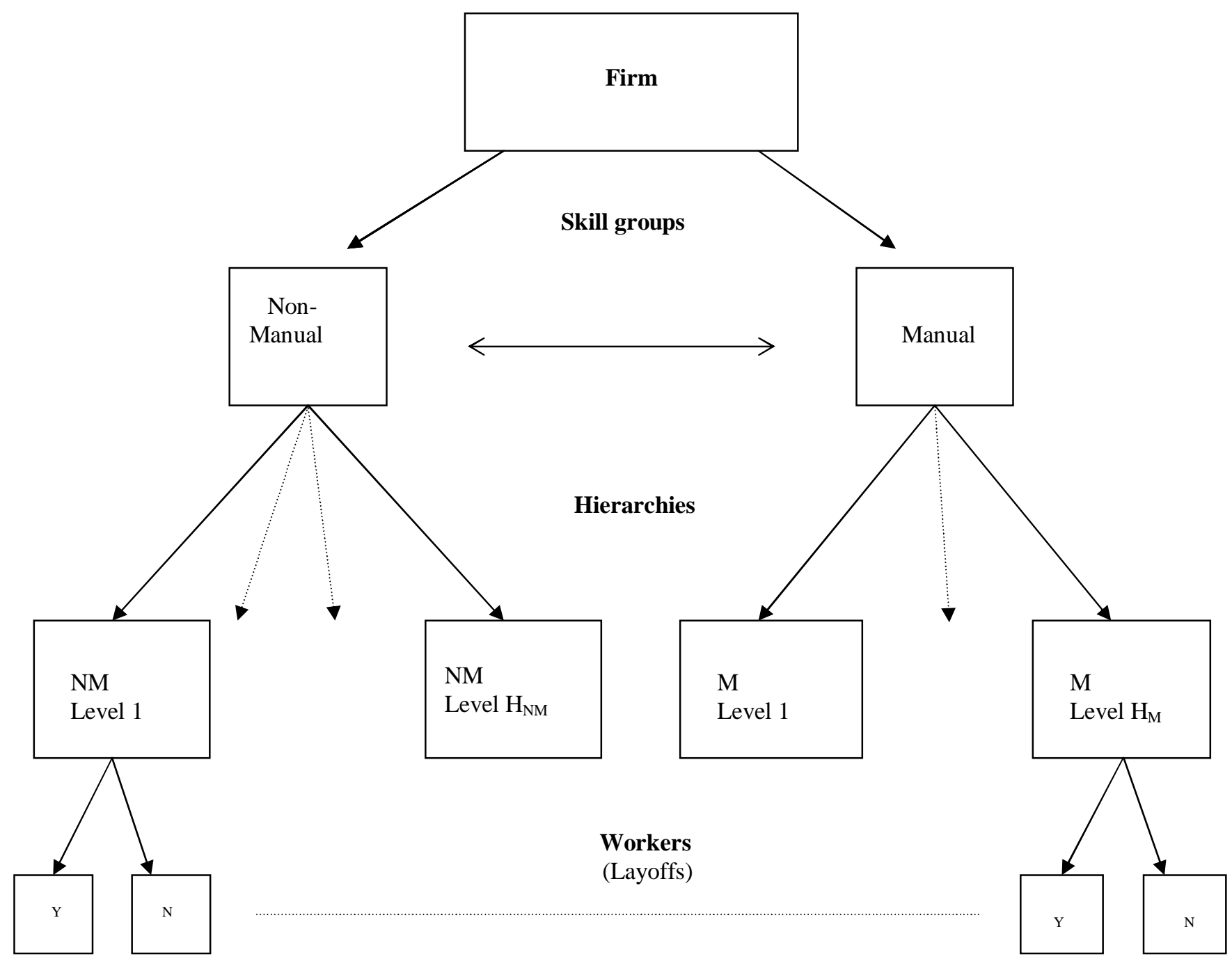

Fig. 1. Tree structure of the firm's restructuring problem

Notes: The tree structure represents the top-down decision structure in the downsizing process. Nonmanual has $\mathrm{H}_{\mathrm{NM}}$ levels, manual $\mathrm{H}_{\mathrm{M}}$. In which $\mathrm{NM}$ stands for non-manual and $\mathrm{M}$ for manual workers. 


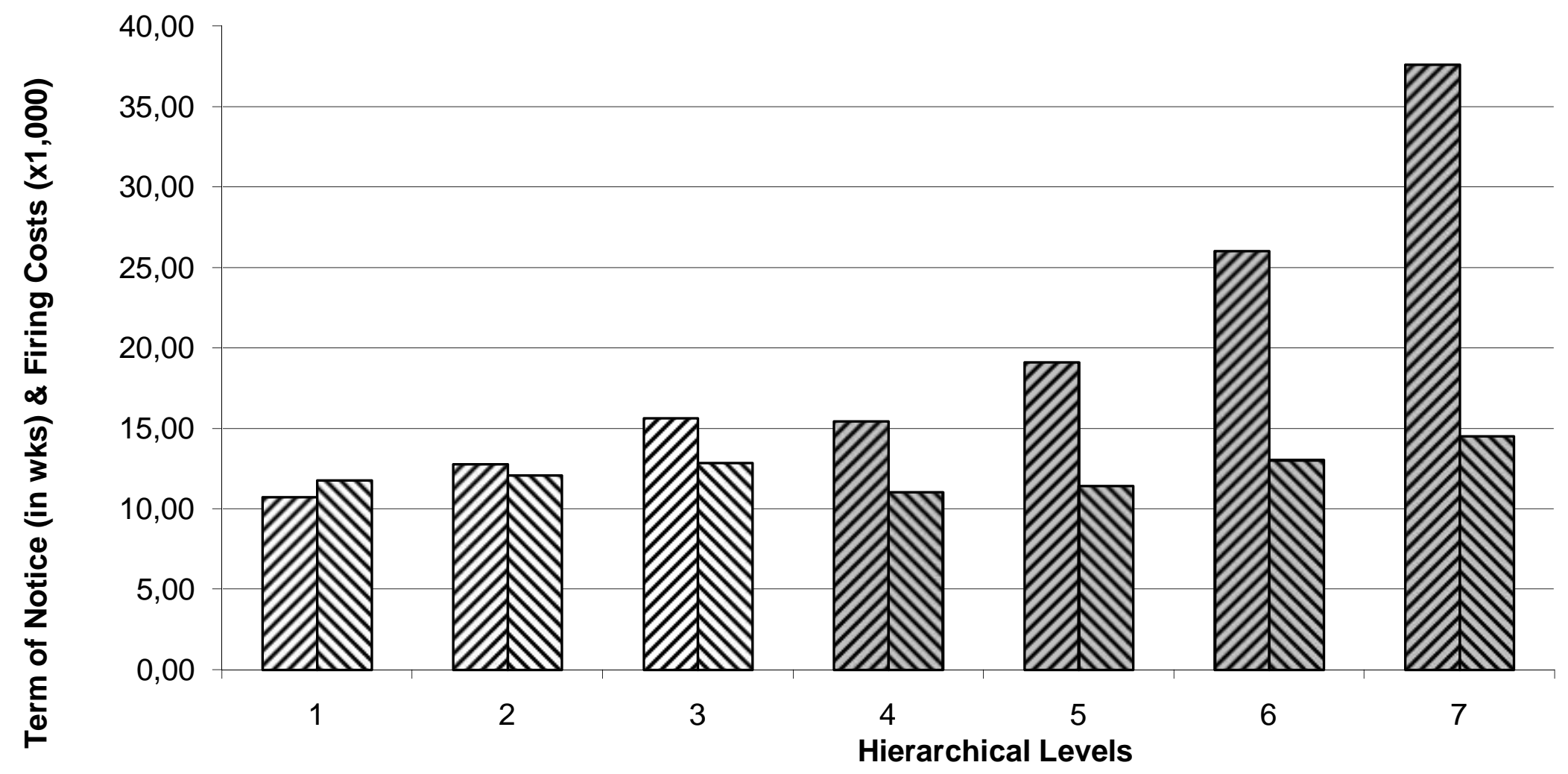

Fig. 1: Term of notice and firing costs

Notes: Firing costs are the left bars (/) and term of notice are the right bars (\). 


\section{Manual Workers}

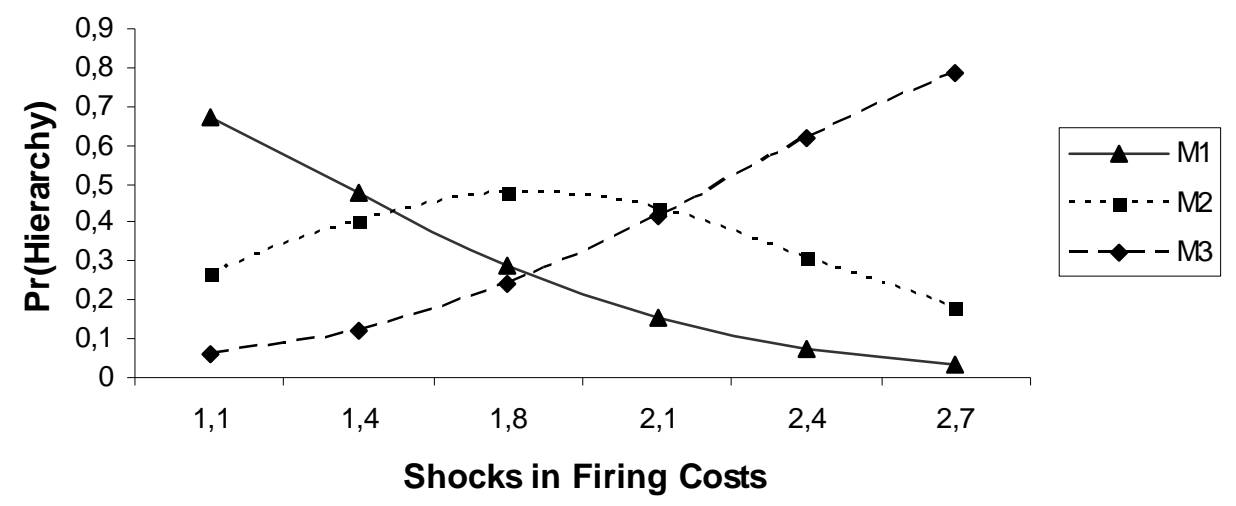

Non-Manual Workers

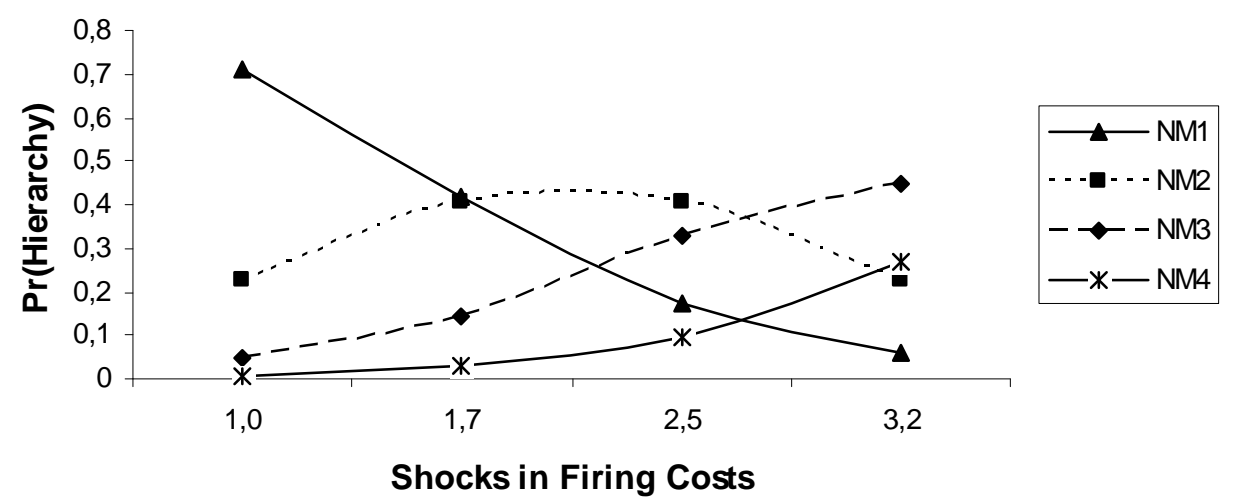

Fig. 3. Effects of shocks in firing costs on job structure of skill groups 


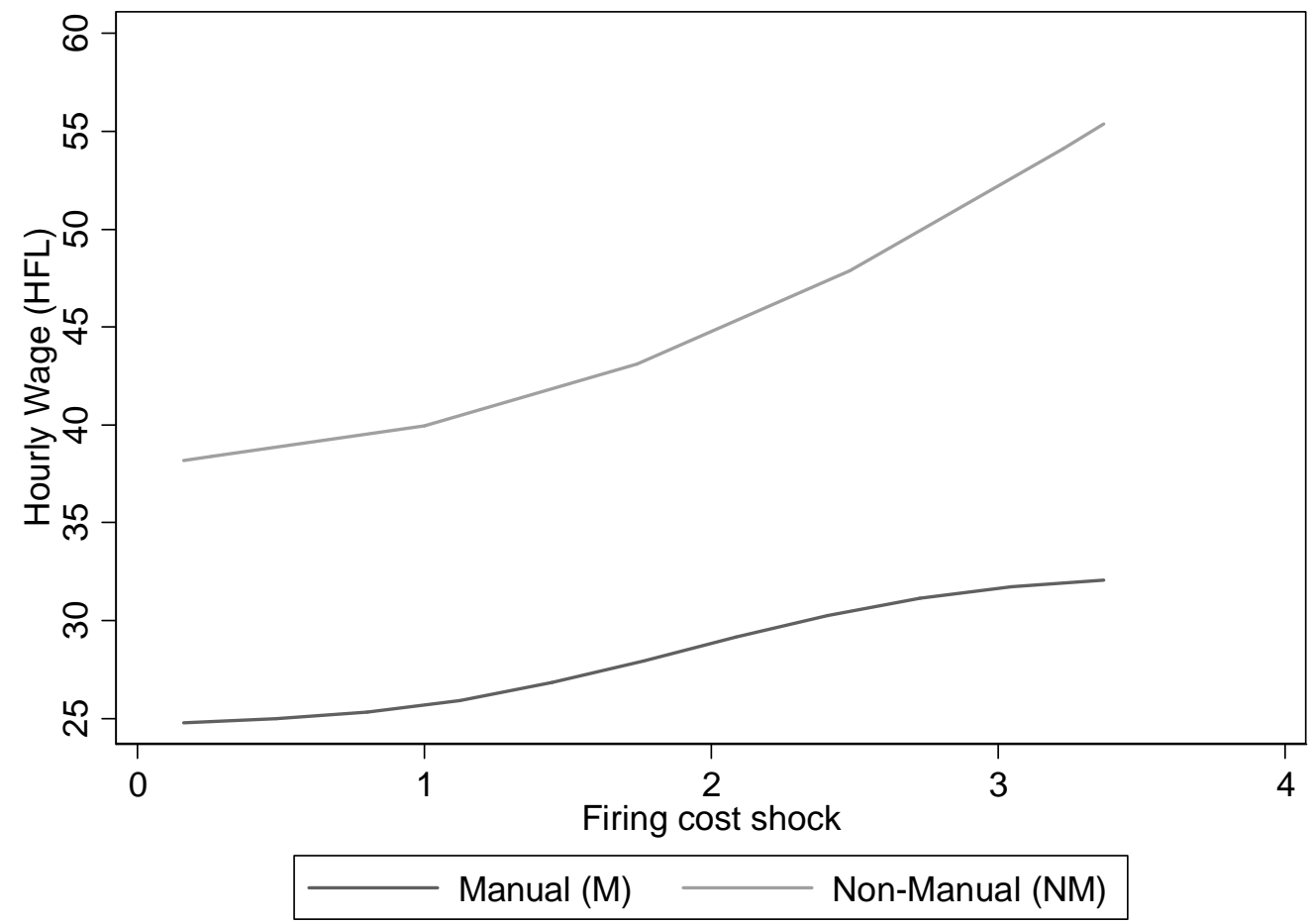

Fig. 4. Firing costs and the effects on the average hourly earnings for different skill groups Notes: The reported hourly wages are in 1996 Dutch guilders $(1 \mathrm{HFL}=0.45 \mathrm{EUR})$ 